\title{
Global warming may freeze the invasion of big-headed ants
}

\author{
Cleo Bertelsmeier • Gloria M. Luque • \\ Franck Courchamp
}

Received: 22 February 2012/ Accepted: 11 December 2012/Published online: 21 December 2012

(C) The Author(s) 2012. This article is published with open access at Springerlink.com

\begin{abstract}
Climate change and invasive species are two of the most serious threats of biodiversity. A general concern is that these threats interact, and that a globally warming climate could favour invasive species. In this study we investigate the invasive potential of one of the " 100 of the world's worst invasive species", the big-headed ant Pheidole megacephala. Using ecological niche models, we estimated the species' potential suitable habitat in 2020, 2050 and 2080. With an ensemble forecast obtained from five different modelling techniques, 3 Global Circulation Models and $2 \mathrm{CO}_{2}$ emission scenarios, we generated world maps with suitable climatic conditions and assessed changes, both qualitatively and quantitatively. Almost one-fifth $(18.5 \%)$ of the landmass currently presents suitable climatic conditions for P. megacephala. Surprisingly, our results also indicate that the invasion of big-headed ants is not only unlikely to benefit from climate change, but may even suffer from it. Our projections show a global decrease in the invasive potential of big-headed ants as early as 2020 and becoming even stronger by 2080 reaching a global loss of $19.4 \%$ of area with favourable climate.
\end{abstract}

Electronic supplementary material The online version of this article (doi:10.1007/s10530-012-0390-y) contains supplementary material, which is available to authorized users.

C. Bertelsmeier $(\bowtie) \cdot$ G. M. Luque · F. Courchamp Ecologie, Systématique and Evolution, UMR CNRS 8079, Université Paris Sud, Orsay Cedex 91405, France

e-mail: cleo.bertelsmeier@u-psud.fr
The decrease is observable in all 6 broad regions, being greatest in the Oceania and lowest in Europe.

Keywords Biological invasions · Climate change · Pheidole megacephala $\cdot$ Niche modelling .

Ensemble forecast $\cdot$ Big-headed ant

\section{Introduction}

Invasive species are generally considered the second most serious threat to global biodiversity and rates of exotic species introductions are ever increasing with human trade and tourism (Vitousek et al. 1997). As a consequence, many native species are displaced, leading to local extinctions of fauna and flora. This ultimately affects community structures and can severely impair ecosystem functioning. Ants are among the worst invasive species (Rabitsch 2011; Holway et al. 2002; Lach and Hooper-Bui 2010). Because they are small, numerous and colonial, they can rapidly colonize a new habitat. One of the most important factors limiting their distribution is climate (Roura-Pascual et al. 2011; Dunn et al. 2009; Sanders et al. 2007; Jenkins et al. 2011) because many features of their biology are temperature or humidity dependent, such as foraging (Brightwell et al. 2010), oviposition rates (Abril et al. 2008), survival (Walters and Mackay 2004), colony dynamics, the structure of foraging networks (Heller and Gordon 2006) and 
dominance over other species (Suwabe et al. 2009). It is therefore crucial to assess their invasive potential under climate change.

Several studies suggest that climate change could exacerbate the threat posed by invasive species, especially poikilotherms, by removing thermal barrier and allowing them to establish at higher latitudes (Brook et al. 2008; Dukes and Mooney 1999; Sala et al. 2000; Walther et al. 2009; Hellmann et al. 2008). Here, we assess the impact of climate change on the potential distribution of the big-headed ant, Pheidole megacephala, which is listed among the " 100 of the worst invasive species" by the IUCN (Lowe et al. 2000). The species is believed to be native to southern Africa and has already invaded various types of habitats worldwide, such as agricultural areas (Wetterer 2007; IUCN SSC Invasive Specialist Group 2012), coastland (Fisher 2012), forests (Fisher 2012; Hoffmann et al. 1999), riparian zones (IUCN SSC Invasive Specialist Group 2012), shrub lands (Wetterer 2007; IUCN SSC Invasive Specialist Group 2012), wetlands (IUCN SSC Invasive Specialist Group 2012; Fisher 2012) and urban areas (Wetterer 2007; IUCN SSC Invasive Specialist Group 2012; Fisher 2012). Although the species is frequently associated with disturbed habitats, it has also been found to invade undisturbed open forests, displacing dominant ant species (Holway et al. 2002) and causing the local loss of several functional groups of ants (Vanderwoude et al. 2000). Pheidole megacephala is very aggressive towards other ant species and has a heightened ability to recruit efficiently many workers and to raid nests of competing ant species (Holway et al. 2002; Dejean et al. 2008). Moreover, it is a highly efficient predator that can capture a wide range of prey, including large invertebrates (Dejean et al. 2007a, b). Where it occurs at high densities, few native invertebrates persist (Wetterer 2007). In a tropical rainforest in Australia P. megacephala abundance was 37-110 times greater than of all the native ants in uninfested sites (Hoffmann et al. 1999). Its negative ecological impact is likely to be greater than that of any other invasive ant species (Wetterer 2007) and only very few successful eradications have been achieved (Hoffmann 2010). As management of invasive ants is notoriously difficult, it is better to take preventive actions and carry out invasion risk assessments in advance, which should include an evaluation of climatic suitability (Hoffmann and Parr 2008).
However, despite its huge consequences for invaded ecosystems, no study so far has assessed the species' current invasive potential area and its trend in the future following climate change.

In this study, our aims are

1. To make global predictions of landmass presenting a currently favourable climate for $P$. megacephala.

2. To estimate the amount of global favourable area under 2 different scenarios of climate change (A2a and B2a) for three points in the future (2020, $2050,2080)$ and to quantify the change in the amount of suitable habitat compared to today.

3. To quantify the regional impact of climate change on the potential habitat-taking 6 broad geographic regions as a proxy (N. America, S. America, Europe, Africa, Asia, Oceania).

In order to model the species' potential habitat, we use ecological niche models, which explain the species' distribution with a set of climatic predictor variables. In recent years, an increasing number of modelling techniques have become available and it has been shown that spatial predictions are sensitive to the choice of modelling algorithms. Furthermore, predictions for future climatic conditions are sensitive to the choice of the Global Circulation Model (GCM) used. To deal with this variability and in order to separate the "signal" from the "noise", one can develop "ensemble forecasts" that define areas of consensual prediction (Araújo and New 2007; Roura-Pascual et al. 2009). We combined models using five different modelling techniques and three GCMs for two Special Report on $\mathrm{CO}_{2}$ Emission Scenarios (SRES) and for four points in time (current, 2020, 2050, 2080). We then compare quantitatively the change in time of suitable areas, both globally and regionally.

\section{Materials and methods}

Species distribution data

Ecological niche models search for a non-random association between environmental predictors and species occurrence data to make spatial predictions of the species' potential habitat. Because the models should include the full set of climatic conditions under which the species can thrive, we decided to include 
occurrence points from both its invaded and native range (following (Liu et al. 2011; Rödder and Lötters 2009; Beaumont et al. 2009; Broennimann et al. 2007). It has been shown that models calibrated based on only native range data often misrepresent the potential invasive distribution and that these errors propagate when estimating climate change impacts (Beaumont et al. 2009; Broennimann et al. 2007).

In total, 208 occurrence records (Fig. 1) were used from the literature, researchers, government agencies, student projects and private collectors, compiled by a public database for ant distributions (Harris and Rees 2004). The species has achieved a pantropical distribution and is known to thrive in tropical and subtropical, warm-temperate and Mediterranean regions (Hoffmann et al. 1999). Therefore, we have removed points, which are clearly outside these climatic conditions and are very likely to be either spurious records or based on indoor locations.

In order to make robust range projections of a species' niche, it is not necessary to include every single location where the species is present but one should aim for a representative cover of all climatic conditions under which the species is known to exist. Our occurrence records come from all continents (except Antarctica, where the species does not occur) and include tropical and temperate locations, over a wide range of latitudes. For models requiring absence data, 10,000 randomly chosen pseudo-absence points were generated from all around the world to provide background data.

\section{Climatic predictors}

We modelled the species' niche based on the 19 bioclimatic variables provided by the Worldclim database (Hijmans et al. 2005). These are frequently used in studies on climatic niches of species and impacts of climate change on species distributions because they have been constructed to have a biological meaning (Wolmarans et al. 2010). The full set of bioclimatic variables was used as model input because the machine learning methods used for niche modelling implicitly deal with variable selection and are unlikely to be improved-and may even be degraded by external modelling methods to pre-select variables (Elith et al. 2011, Guyon and Elisseeff 2003). Machine learning methods are a set of algorithms that learn the mapping function or classification rule inductively from the input data. They use cross-validation to test model performance on held-out data within the modelling process (Elith et al. 2006). The bioclimatic variables (full list in the Electronic Supplementary

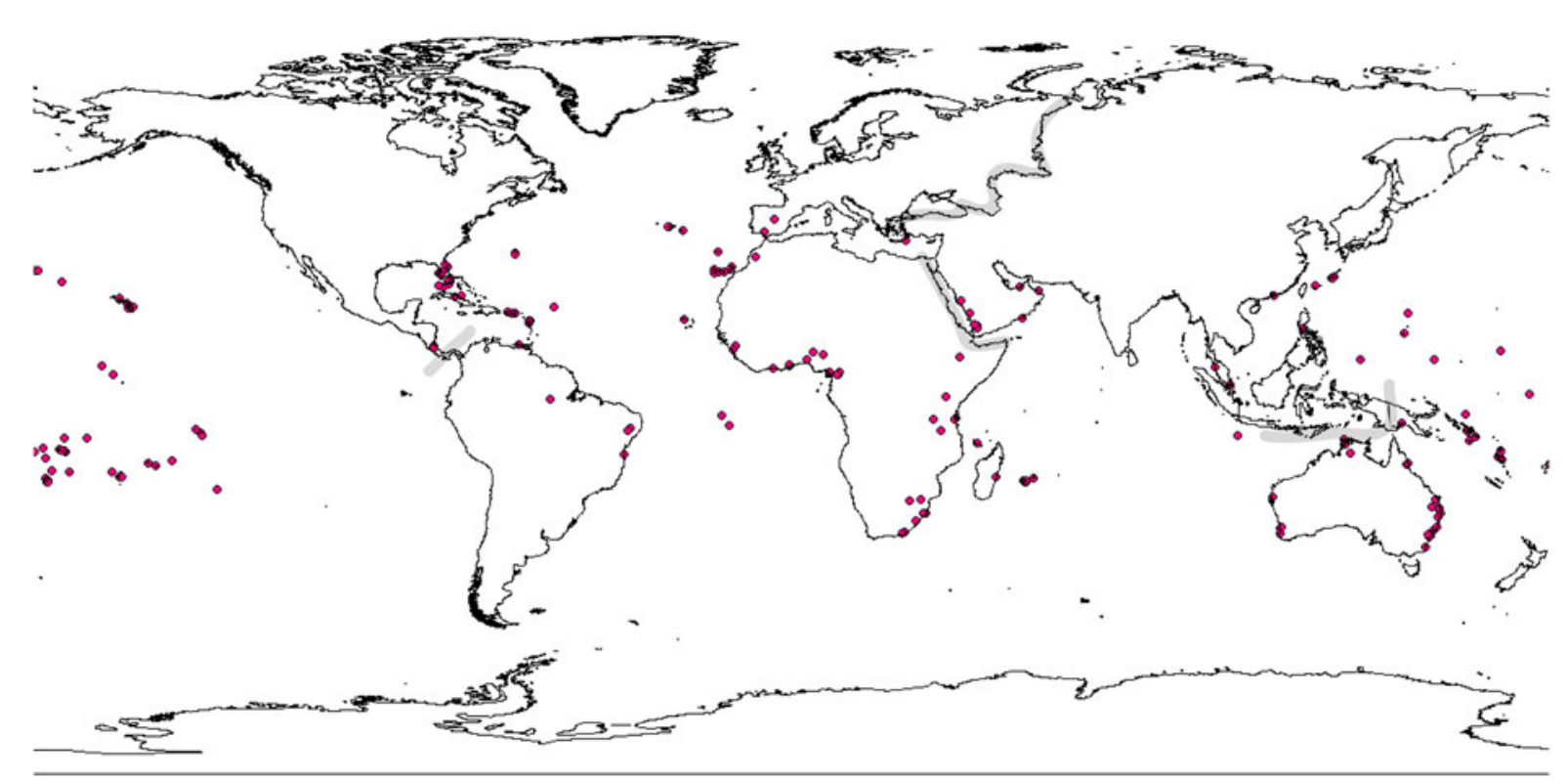

Fig. 1 Documented occurrences of $P$. megacephala in its native and invaded range (red dots). The grey lines indicate the boundaries between the geographic regions that we used for the analysis of favourable habitat. (Color figure online) 
Material, fig. S1) are derived from monthly temperature and rainfall values from 1960 to 1990 (Hijmans et al. 2005). They represent annual trends (e.g. mean annual temperature, annual precipitation), seasonality (e.g. annual range in temperature and precipitation) and extreme or limiting environmental factors (e.g. temperature of the coldest and warmest month, and precipitation of the wet and dry quarters) (Hijmans et al. 2005). We used a spatial resolution of $10 \mathrm{arcmin}$ (approx. $18.5 \times 18.5 \mathrm{~km}$ pixel).

Future climatic data was provided by the 4th IPCC assessment report (GIEC 2007). The projections are calibrated and statistically downscaled using the WorldClim data for 'current' conditions and therefore the projections can be compared. In order to consider a range of possible future climates, we modelled the species' potential future distribution based on downscaled climate data from three different GCMs provided by different climate modelling centres: The CCCMA-GCM2 model, the CSIRO-MK2 model and the HCCPR-HADCM3 model (GIEC 2007). In addition, projections for two different SRES $\mathrm{CO}_{2}$ emission scenarios were included in our models: the optimistic B2a scenario $\left(\mathrm{CO}_{2}\right.$ concentration $800 \mathrm{ppm}, 1.4-3.8{ }^{\circ} \mathrm{C}$ temperature increase) and the pessimistic $\mathrm{A} 2$ a scenario ( $\mathrm{CO}_{2}$ concentration $1,250 \mathrm{ppm}, 2-5.4{ }^{\circ} \mathrm{C}$ temperature increase) (GIEC 2007).

\section{Ecological Niche Modelling}

Five different machine learning modelling techniques were used to generate the ensemble forecasts. Machine learning methods are among the recently developed tools especially designed for prediction (Lorena et al. 2011) and it has been claimed that their predictive performance exceeds that of more conventional techniques (Elith and Leathwick 2009).

All models were run using the ModEco Platform with default parameters (Guo and Liu 2010). The first two models are using a new generation of learning algorithms: Support Vector Machines (SVMs) (Cristianini and Schölkopf 2002; Guo et al. 2005), 1-classSVMs (parameters: kernel = Radial Base function, $\gamma=1, \quad v=0.05$ ) and 2-class-SVMS (parameters: type $=$ C_SVC, kernel = Radial Base function, $\gamma=3$, Cost $=1$ ). In addition, we used Artificial Neural Networks (ANN) (parameters: type = Backpropagation ANN, Momentum $=0.3$, Learning rate $=0.1) \quad$ (Manel et al. 1999; Franklin 2009;
Maravelias et al. 2003) and Classification Trees (CT) (parameters: type $=$ iterative, Number of trials $=5$, Window size $=10$, Pruning level $=0.25$ ) (De'ath and Fabricius 2000). The result was an average across 10 Classification Trees iterations of the model algorithm. Finally, we used the Maximum Entropy method (Maxent), a common model algorithm for niche modelling (Stiels et al. 2011; Jimenez-Valverde et al. 2011; Murray et al. 2011; Jarnevich and Reynolds 2011; Bradley et al. 2010; Ficetola et al. 2010; Ward 2007; Roura-Pascual et al. 2009, Phillips et al. 2006).

Although these machine-learning methods are known for their high predictive power, there are comparatively few tools available for visualizing and analysing the contribution of different variables. This is partly because techniques such as ANN's create synthetic variables from the original set, leading to a complex and "black box" nature of the model (Elith and Leathwick 2009). Maxent is one of the few machine-learning models to possess techniques for ecological insight. Therefore, we present jacknife tests of variable contribution in Maxent, to indicate which factors are most important in determining the current distribution of the species (Phillips et al. 2006).

The different modelling techniques, SRES scenarios and GCMs are used in different combinations in order to obtain a range of possible future habitat maps (Fig. 2). In a second step, the individual models were combined into consensus models reducing uncertainties of each of the models. The idea of consensual forecasts is to separate the signal from the "noise" associated with the errors and uncertainties of individual models, by superposing the maps based on individual model outputs. Areas where these individual maps overlap, are defined as areas of "consensual prediction" (Araújo and New 2007). This is different from averaging the individual projections, as the area predicted by the consensual forecast can be smaller than any individual forecast if there is little spatial agreement (i.e. overlap) between individual forecasts. Simple averaging across individual forecasts is considered unlikely to match the reality and therefore ensemble averages or confidence limits for the consensual prediction are classically not calculated (Araújo and New 2007).

The individual model outputs (i.e. the probability of presence in each pixel) were weighted according to their AUC in order to enhance the contribution of models with higher model performance values (see 


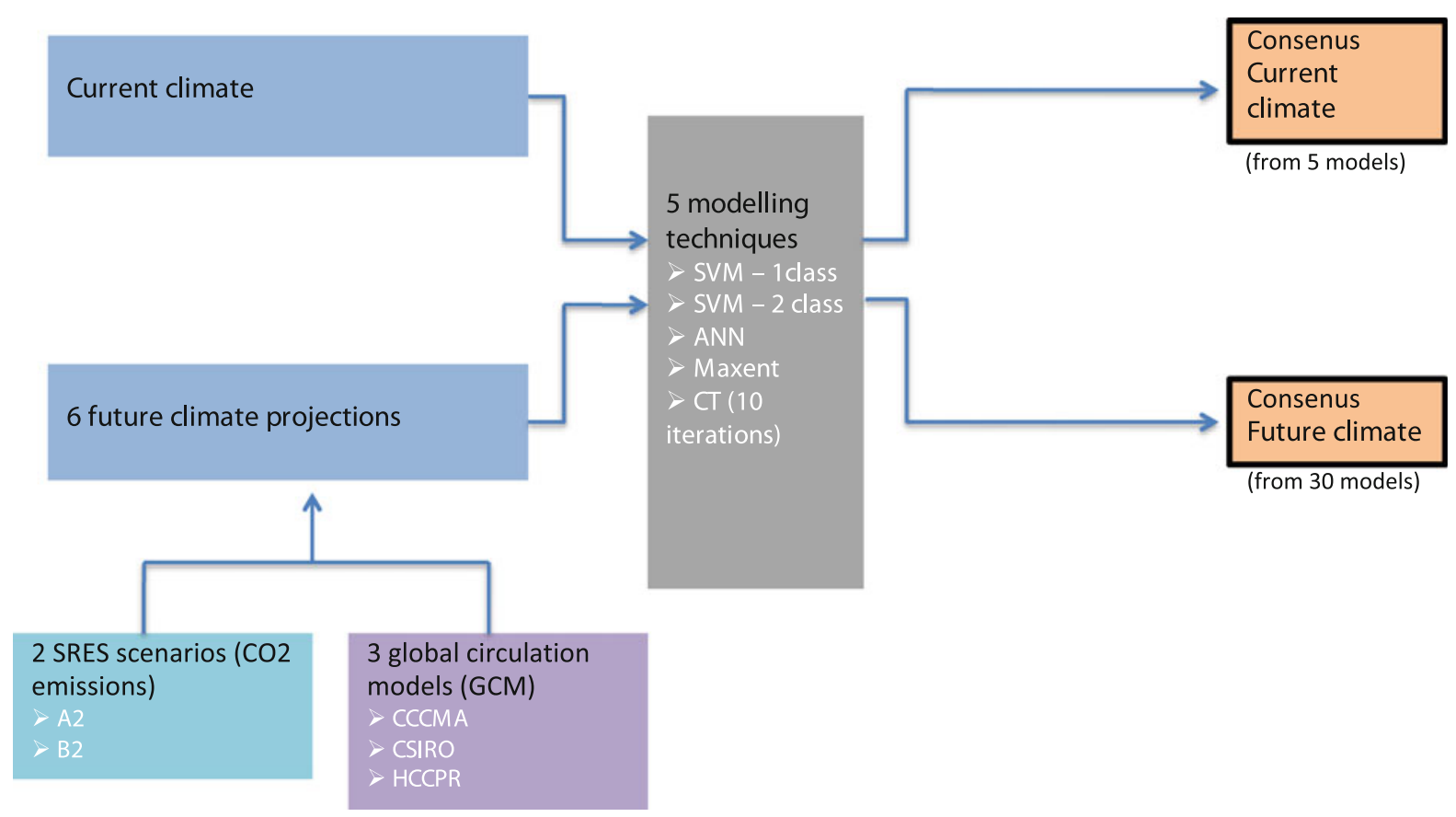

Fig. 2 Model design to obtain estimates of areas of suitable habitat for Pheidole megacephala in the present and in the future. The species' potential future distribution is modelled using $2 \mathrm{CO}_{2}$ emission scenarios, 3 climate models (GCM) and

(Roura-Pascual et al. 2009)). We obtained a continuous projection of the consensus model with a probability of the species being present assigned to each pixel.

Ensemble models were generated for current climate (consensus across models using the five modelling techniques), for the A2 scenario (consensus including 15 individual projections in total with climate data from $3 \mathrm{GCMs}$ and 5 modelling techniques) and for the $\mathrm{B} 2$ scenario (again $3 \times 5$ projections). A total climate change forecast model was also generated, including all 30 individual projectionseach based on a different combination of $\mathrm{CO}_{2}$ scenario $\times$ GCM $\times$ modelling technique. This yields a consensus projection for one particular point in time (see Fig. 2). Consequently we obtained a single value per consensus model, which we decided to illustrate later in the form of histograms. But as the underlying idea of consensus models is to incorporate the variation, there cannot be error bars of the variation between single models in the figures. The modelling process was repeated to generate consensus predictions for 2020, 2050 and 2080). five modelling methods, yielding a total of 30 individual models that were combined in the total consensus model. This process was repeated three times, in order to get projections for 2020 , 2050 and 2080

Assessing favourable habitat

Potential habitat suitability was assessed in two ways. First, a classical threshold rule was applied, whereby all pixels in which the probability of presence exceeded 0.5 were classified as "favourable" habitat (Franklin 2009). This is frequently used for binary classification in the context of species distribution modelling (Franklin 2009; Klamt et al. 2011). For specific uses of our models, it might be interesting to minimize the chance of either over- or under-prediction of potential habitat (omission or commission errors) and to apply a different threshold. For example, for management decisions it could be better to apply a more "prudent" (lower) threshold that lowers the probability of omission errors. To allow these user-specific applications of our models, we also provide maps with a continuous output with a probability of presence between 0 and 1 (with 0.1 intervals), although we consider only habitat as favourable above a probability of presence of 0.5 . Spatial analyses were carried out using DIVA-GIS program, developed by Hijmans et al. (2001). 
Second, in order to evaluate whether the "quality" of the available habitat has changed, we divided the "favourable" habitat into five classes, ranging from "low" $(0.5<p<0.6)$ to "excellent" suitability $(0.9<p<1)$ and compared change of classes over time.

\section{Model validation}

Model robustness has been evaluated with the AUC of the ROC curve, which is a nonparametric thresholdindependent measure of accuracy that is commonly used to evaluate species distribution models (Ward 2007; Roura-Pascual et al. 2009; Manel et al. 1999; Pearce and Ferrier 2000). We used the AUC because it is not a measure of model performance that depends on the classification threshold, which has been selected, and is easily interpretable as the probability that a model discriminates correctly between presence and absence points (Pearce and Ferrier 2000; RouraPascual et al. 2009). AUC values can range from 0 to 1 , where a value of 0.5 can be interpreted as a random prediction. AUC between 0.5 and 0.7 are considered low (poor model performance), 0.7-0.9 moderate and $>0.9$ high (Franklin 2009 and references therein). In addition, several threshold-dependent measures were used to summarize model performance, including sensitivity (proportion of correctly classified presences), specificity (proportion of correctly classified absences), overall accuracy (proportion correctly classified presences and absences) and Cohen's Kappa (Fielding and Bell 1997). Kappa ranges from -1 to 1 and values of 0 are no better than produced by chance. In general, models with a Kappa $>0.4$ are considered to be good (Fielding and Bell 1997).

In addition, a one-way ANOVA was conducted using R software version 2.12.2 to compare differences in individual model forecasts due to differences in $\mathrm{CO}_{2}$ emission scenarios, GCMs and modelling methods.

\section{Results}

Models achieved good to excellent performance with AUC ranging from 0.865 to 0.981 and Kappa ranging from 0.534 to 0.793 . That indicates overall a good to very good ability to predict the species presence (Table 1). There was no significant difference between projections under different $\mathrm{CO}_{2}$ emission scenarios $\left[\mathrm{F}_{(1,28)}=0,01, p=0,945\right)$. The difference between projections based on different GCMs $\left[\mathrm{F}_{(2,27)}=3,87, p=0,033\right)$ and different modelling methods $\left[\mathrm{F}_{(4,25)}=12, p<0,001\right)$ were significant, but all individual models were showing the same trend (Fig. S2, Electronic Supplementary Material). The jacknife test of variable importance carried out with Maxent shows that the climatic variable with the best predictive power when used in isolation is "temperature annual range" (max temperature of the warmest month minus min temperature of the coldest month). Its percentage contribution to the final Maxent model is $24.7 \%$. The variable that decreases the gain most when omitted is "temperature seasonality" (for variable description see (Hijmans et al. 2005)), with a permutation importance of $25.8 \%$. Both, "temperature annual range" and "temperature seasonality" are negatively related to occurrence of the species, i.e. $P$. megacephala is more likely to occur in places with relatively low temperature range and variability. Further, the third and fourth most important variables were "diurnal range" and "precipitation of the coldest quarter", which have a percentage contribution to the final Maxent model of $14.5 \%$ and $9.1 \%$ respectively.

\section{Current potential habitat worldwide}

Under the current climate, the ensemble forecast model predicts that $18.5 \%$ of global landmass presents favourable climatic conditions potentially allowing the species to establish, with $4.9 \%$ of total landmass presenting low suitability, $4.8 \%$ medium, $2.4 \%$ high, $3.5 \%$ very high and $2.8 \%$ excellent suitability.

The greatest proportion of favourable area is found in South America, Africa, Oceania and Asia (in that order of importance), whereas relatively little suitable habitat is found in Europe and North America (4.1\% and $4.5 \%$ of the total suitable area, respectively, Fig. 3a). Currently the species is already a global invader and established on all continents. However, this shows that it could expand much further, especially in the regions that present a high percentage of climatically favourable landmass. The total favourable landmass is unequally distributed among the continents (Fig. 3b), only $1 \%$ of the total favourable landmass for the species is found in Europe, $5 \%$ in North America, $13 \%$ in Asia, $17 \%$ in Oceania, $30 \%$ in South America and $34 \%$ in Africa. 
Table 1 Summary of model performances of the five machine learning algorithms

\begin{tabular}{llllll}
\hline Modelling technique & AUC & Sensitivity & Specificity & Kappa & Overall accuracy \\
\hline 1 Class SVM & 0.872 & 0.784 & 0.75 & 0.534 & 0.767 \\
2 Class SVM & 0.865 & 0.793 & 0.808 & 0.601 & 0.8 \\
ANN & 0.955 & 0.649 & 0.923 & 0.572 & 0.897 \\
Maxent & 0.921 & 0.736 & 0.86 & 0.596 & 0.798 \\
CT & 0.981 & 0.832 & 0.962 & 0.793 & 0.897 \\
\hline
\end{tabular}

Favourable habitat following climate change

The amount of potential habitat is clearly decreasing by 2080 under either $\mathrm{CO}_{2}$ emission scenarios, $\mathrm{A} 2$ and $\mathrm{B} 2$ (Fig. 4a, b). The overall decrease of potential habitat relative to the current potential habitat is $-21 \%$ under the A2 scenario, $-17 \%$ under B2 scenario and $-19.4 \%$ in the overall consensus model that combines forecasts under both scenarios. Moreover, among areas that still present a suitable climate, one can also observe a clear change in the "quality" of the habitat, with "excellent" and "very high suitability" areas both decreasing (Fig. 5a).

Overall, the potential habitat is predicted to decrease in all of the 6 broad geographic regions, but the magnitude of this decrease varies. The loss of potential habitat is highest in the Oceania region (-28\%), followed by North America (-27\%), South America (-18.8\%), Africa $(-18.8 \%)$, Europe $(-13.7 \%)$ and Asia (-9.2\%) (Fig. 5b).

Suitable climatic conditions are steadily decreasing over time for $P$. megacephala. Compared to current suitable area, its potential habitat will decrease globally by $11.1 \%$ in 2020 , by $15.5 \%$ in 2050 and by $19.4 \%$ in 2080 (Fig. 5c).

\section{Discussion}

The ensemble forecasts predict that nearly a fifth of global landmass $(18.5 \%)$ is currently climatically suitable for $P$. megacephala, which is worrying given the dramatic impact this invader is known to cause (e.g. Wetterer 2007; Vanderwoude et al. 2000; Hoffmann and Parr 2008). South America is the continental region with the currently largest proportion of suitable habitat (54\% South American landmass is favourable) and Europe is the lowest (4.1\%). However, the projections following climate change show very

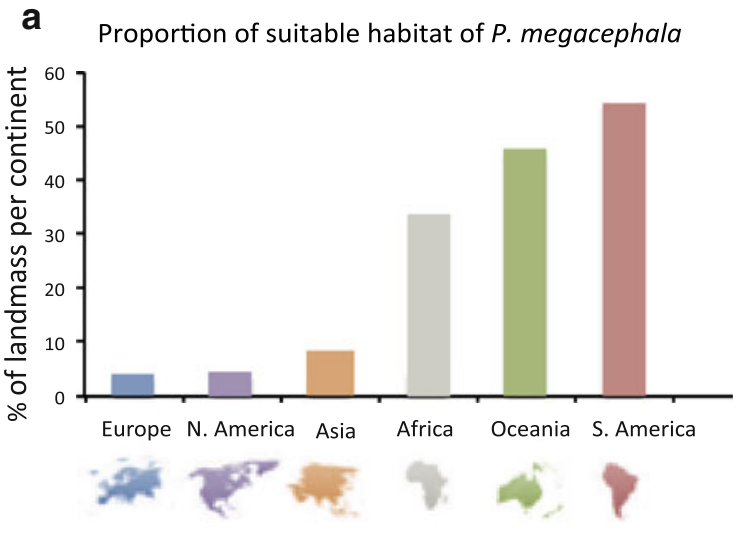

\section{b}

Distribution of suitable habitat of $P$. megacephala

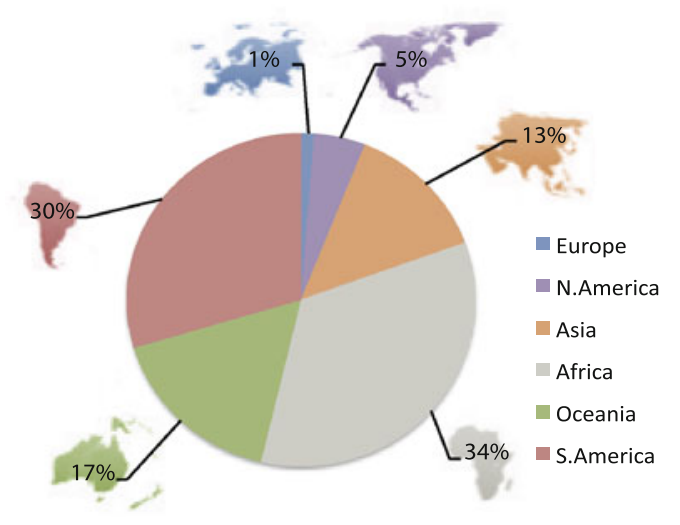

Fig. 3 Regional distribution of suitable areas of P. megacephala: a proportion of each region that is suitable, $\mathbf{b}$ distribution of suitable areas per region

surprising results. Contrary to what is generally believed, our results suggest that climate change will not increase invasion risks of $P$. megacephala. On the contrary, the potential habitat will decrease, leading to a substantial loss of global suitable habitat, varying 

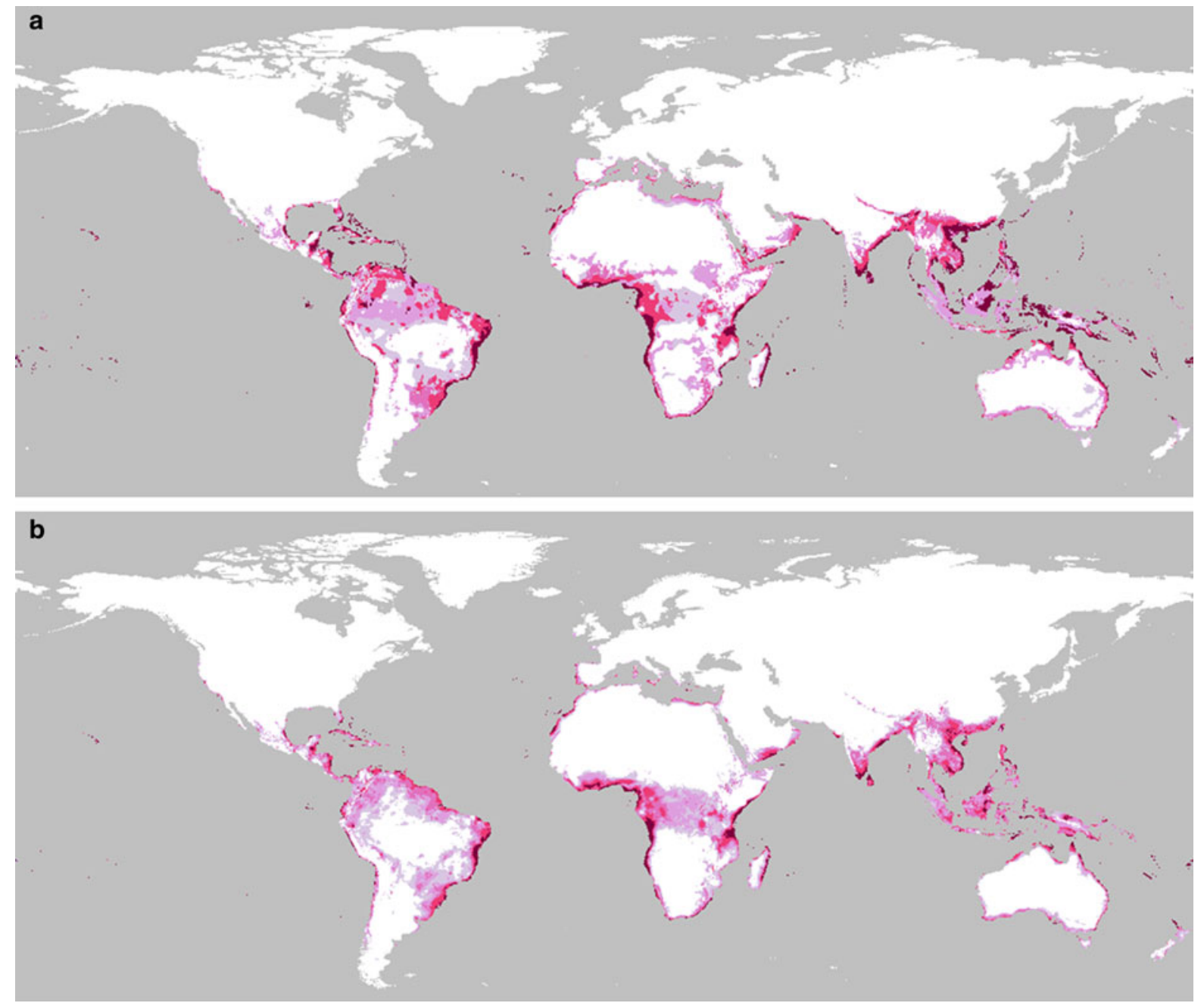

Fig. 4 Maps of potential habitat. Climatic suitability ranges from "low" (light red) to "excellent" (dark red). a Current climatic conditions. b Consensus model of A2 + B2 scenario. (Color figure online)

between 17 and $21 \%$ (depending on the scenarios of climate change considered, A2 or B2). In addition, the decrease in potential habitat can be seen all over the world, although it is heterogeneous across the 6 continental regions considered. It is highest in the Oceania region $(-28 \%)$ and lowest in Asia (-9.2\%). Loss of potential habitat can be seen as early as 2020 but will be accentuated by 2050 and even more so by 2080.

These results might help focus management and conservation efforts, in particular by providing regional information on the relative risk of invasion of this species. Overall, the decrease in global favourable landmass of one of the worst invasive species (Lowe et al. 2000) is encouraging for conservation. However, it should be kept in mind that the metric used here is potential (current and future) habitat of suitable climatic conditions, and not actual invaded areas, neither current nor future. That means that the potential habitat of the species is greater than its actual distribution. Consequently, even though it will decrease, it is possible that the future potential habitat will still be greater than the current distribution of the species. Overall, one might therefore observe a range increase of the species by 2080 compared to the current distribution. However, this increase could have been much greater if climate change had not reduced the potentially favourable landmass. 
a Changes in quality category of suitable habitat

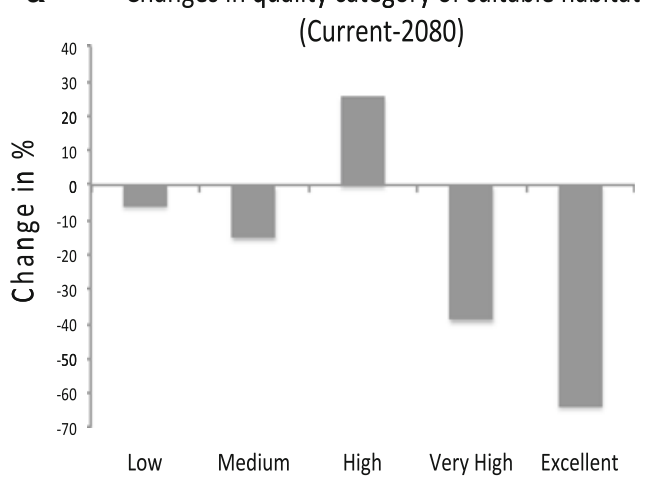

b Decrease in favourable habitat
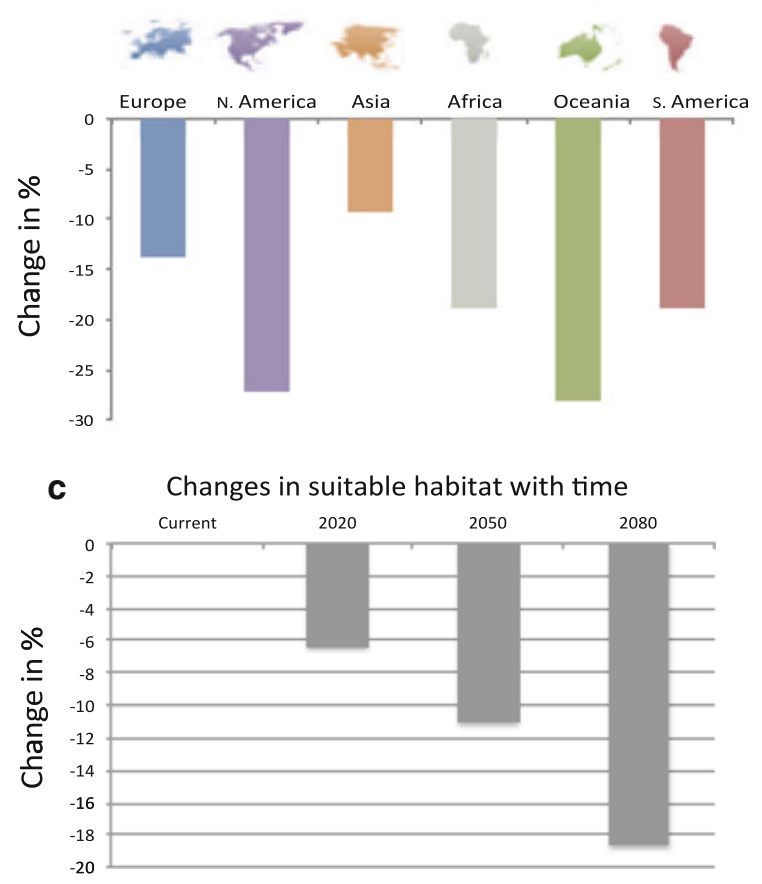

Fig. 5 a Changes in the future potential habitat relative to current potential habitat (in \%). The different categories reflect the «quality» of the potential habitat under the consensus climate change model. There are no error bars because a consensus model has been used. b Change (in \%) of favourable habitat in the six geographic regions. c Change of potential habitat over time

In addition, interpretation of these results should be made in awareness of the set of strong assumptions classically made by using niche models (Guisan and Thuiller 2005; Austin 2007). For example, all niche models assume niche conservation, which implies that the species is at equilibrium with its environment and will not change its requirements in space (new potential habitat) or time (future climate scenarios). However, invasive species may have non-equilibrium distributions (Sutherst and Bourne 2009) and expand into these non-analogue climates, which can be accompanied by a niche shift or filling of a preadapted niche (Petitpierre et al. 2012; Webber et al. 2012). There are documented cases of niche shifts in invasive species following genetic bottlenecks or rapid evolution in the new habitat leading to an invasive niche that differs from the native niche (Gallagher et al. 2010; Broennimann et al. 2007; Pearman et al. 2008) (but see (Fitzpatrick et al. 2007)).

Moreover, it is possible that the current distribution of the species is not limited only by climatic factors. A general weakness of niche modelling is that biotic interactions are not taken into account. However, a global analysis of the relative role of different determinants of invasion success of the Argentine ant has shown that biotic resistance had a very weak influence in regions with high climatic suitability. Biotic interactions became important in determining invasion success only in less climatically favourable regions (Roura-Pascual et al. 2011). It can be argued that in the case of many invasive species, and in particular $P$. megacephala, native fauna has been shown not to resist much and therefore the distribution of the species is probably not much limited by natural enemies, including competitors (Roura-Pascual et al. 2011; Dejean et al. 2007b, 2008; Hoffmann and Parr 2008).

Our aim here was to produce forecasts at a global scale, at which climate is the most important factor determining the distribution of invasive ants (e.g. Roura-Pascual et al. 2011; Dunn et al. 2009; Sanders et al. 2007; Jenkins et al. 2011). However, if one aims to produce more models at a very fine scale, it will enhance model precision to include additional variables - especially human modification of habitats (Roura-Pascual et al. 2011). Microclimate may also be an important factor to consider at a smaller scale. For example, it has been shown that the abundance of invasive Argentine ants increased in plots with increased moisture levels due localized watering of plants (Menke and Holway 2006). Furthermore, the nest of the ant colony can play an important role in providing a thermal refuge, as the temperature experienced by the colony at the microhabitat scale can be different from the air temperature recorded by climate stations (Ward 2007).

Many uncertainties are associated with the models of future climatic conditions under different scenarios 
of global climate change and different $\mathrm{CO}_{2}$ emission scenarios. Different assumptions in atmospheric physics can lead to substantially different GCMs. These divergences are classically considered as "noise" and consensus models are used to get a picture of the general tendency (Araújo and New 2007). We took into account a wide range of possible future climatic conditions by choosing three of the most widely used GCMs and two $\mathrm{CO}_{2}$ emission scenarios. Similarly, to account for variability in the projections due to different modelling algorithms, we included five different modelling techniques that have all been applied to ecological modelling. Our results show that these models achieved good to excellent performance in their ability to predict the species presence.

The "signal" from the consensus models is that an enormous area, which represents approximately $1 / 5$ of global landmass, currently has favourable climatic conditions for $P$. megacephala, which may allow the species to extend its invasive range further than it already has. Even though this global invader is present on all continents, it is likely that it will spread further, with devastating impacts on local biodiversity. However, climate change will not exacerbate this. On the contrary, P. megacephala will suffer a substantial loss of potential habitat in all regions and over all time steps considered following climate change. This is opposite to classical views of global climate change exacerbating the effects and increasing the ranges of many invaders, especially those currently limited by climate. The general consensus has been that invasive species will follow a path opposite to the rest of the biodiversity in the future, thereby interacting synergistically with climate change to increase the overall threat on biodiversity (Brook et al. 2008; Dukes and Mooney 1999; Sala et al. 2000; Walther et al. 2009; Hellmann et al. 2008). Our results show this is not necessarily the case. In fact, it may well be that many invasive species will follow the global trend of biodiversity in general, which is predicted to decrease substantially (Bellard et al. 2012). In this regard, only very few studies so far have suggested that some invasive species could also decrease following climate change (Walther et al. 2009). However, one other invasive ant known for its devastating impacts, the Argentine ant (Linepithema humile) might similarly show a moderate decline by 2050 (Roura-Pascual et al. 2004; Cooling et al. 2011). But the Argentine ant may lose habitat due to "geometric" reasons because its climatic envelope will shift to higher latitudes, expanding towards the poles and shrinking at tropical latitudes. Pheidole megacephala, on the other hand, will experience very little shifts in potential habitat. The envelope presenting favourable climatic conditions will mostly shrink.

Therefore, it is possible that the worst invasive species of today may not be the worst invasive species of tomorrow. Given this unexpected result, it would be interesting to carry out more studies on invasive species to assess potential trends of invasive species following global change.

An important conclusion from this study is that devastating invasive species like $P$. megacephala may fail to invade some areas where the habitat is currently suitable. Therefore, despite clear, negative impacts on biodiversity globally (Bellard et al. 2012), climate change could also have an indirect positive effect on some aspects, for example by reducing the potential range of problematic species that are the cause of numerous local species extinctions. Management efforts to control P. megacephala should continue, as a very large proportion of the Earth' landmass is currently favourable. Even if the species is going to suffer from a global range reduction of up to $21 \%$ under a pessimistic $\mathrm{CO}_{2}$ emission scenario, very large areas will still present suitable climatic conditions for this highly problematic invasive species.

Acknowledgments We thank two anonymous referees for their help in improving an earlier version of this manuscript. This paper was supported by Région Ile-de-France (03-2010/ GV-DIM ASTREA) and ANR (2009 PEXT 010 01) grants.

Open Access This article is distributed under the terms of the Creative Commons Attribution License which permits any use, distribution, and reproduction in any medium, provided the original author(s) and the source are credited.

\section{References}

Abril S, Oliveras J, Gómez C, Gomez C (2008) Effect of temperature on the oviposition rate of Argentine ant queens (Linepithema humile Mayr) under monogynous and polygynous experimental conditions. J Insect Physiol 54:265-272

Araújo MB, New M (2007) Ensemble forecasting of species distributions. Trends Ecol Evol 22:42-47

Austin M (2007) Species distribution models and ecological theory: a critical assessment and some possible new approaches. Ecol Model 200:1-19

Beaumont LJ, Gallagher RV, Thuiller W, Downey PO, Leishman MR, Hughes L (2009) Different climatic envelopes 
among invasive populations may lead to underestimations of current and future biological invasions. Divers Distrib 15:409-420

Bellard C, Bertelsmeier C, Leadley P, Thuiller W, Courchamp F (2012) Impacts of climate change on the future of biodiversity. Ecol Lett. doi:10.1111/j.1461-0248.2011.01736.x

Bradley BA, Wilcove DS, Oppenheimer M (2010) Climate change increases risk of plant invasion in the Eastern United States. Biol Invasions 12:1855-1872

Brightwell R, Labadie P, Silverman J (2010) Northward Expansion of the Invasive Linepithema humile (Hymenoptera: Formicidae) in the Eastern United States is Constrained by Winter Soil Temperatures. Environ Entomol 39:1659-1665

Broennimann O, Treier UA, Muller-Scharer H, Thuiller W, Peterson AT, Guisan A (2007) Evidence of climatic niche shift during biological invasion. Ecol Lett 10:701-709

Brook BW, Sodhi NS, Bradshaw CJA (2008) Synergies among extinction drivers under global change. Trends Ecol Evol 23:453-460

Cooling M, Hartley S, Sim DA, Lester PJ (2011) The widespread collapse of an invasive species: Argentine ants (Linepithema humile) in New Zealand. Biol Lett. doi: 10.1098/rsbl.2011.1014

Cristianini N, Schölkopf B (2002) Support vector machines and kernel methods, the new generation of learning machines. AI Mag 23:31-41

De'ath G, Fabricius KE (2000) Classification and regression trees: a powerful yet simple technique for ecological data analysis. Ecology 81:3178-3192

Dejean A, Kenne M, Moreau CS (2007a) Predatory abilities favour the success of the invasive ant Pheidole megacephala in an introduced area. J Appl Entomol 131:625-629

Dejean A, Moreau CS, Uzac P, Le Breton J, Kenne M (2007b) The predatory behavior of Pheidole megacephala. CR Biol 330:701-709

Dejean A, Moreau CS, Kenne M, Leponce M (2008) The raiding success of Pheidole megacephala on other ants in both its native and introduced ranges. CR Biol 331:631-635

Dukes JS, Mooney HA (1999) Does global change increase the success of biological invaders? Trends Ecol Evol 14:135-139

Dunn RR et al (2009) Climatic drivers of hemispheric asymmetry in global patterns of ant species richness. Ecol Lett 12:324-333

Elith J, Leathwick JR (2009) Species distribution models: ecological explanation and prediction across space and time. Annu Rev Ecol Evol Syst 40:677-697

Elith J, Graham C, Anderson R, Dudik M (2006) Novel methods improve prediction of species distributions from occurrence data. Ecography 2:129-151

Elith J, Phillips SJ, Hastie T, Dudik M, Chee YE, Yates CJ (2011) A statistical explanation of MaxEnt for ecologists. Divers Distrib 17:43-57

Ficetola GF, Maiorano L, Falcucci A, Dendoncker N, Boitani L, Padoa-Schioppa E, Miaud C, Thuiller W (2010) Knowing the past to predict the future: land-use change and the distribution of invasive bullfrogs. Glob Change Biol 16:528-537

Fielding AH, Bell JF (1997) A review of methods for the assessment of prediction errors in conservation presence/ absence models. Environ Conserv 24:38-49
Fisher BL (2012) Antweb. Species: Pheidole (megacephala) megacephala. http://www.antweb.org. Accessed on 24 January 2012

Fitzpatrick MC, Weltzin JF, Sanders NJ, Dunn RR (2007) The biogeography of prediction error: why does the introduced range of the fire ant over-predict its native range? Glob Ecol Biogeogr 16:24-33

Franklin J (2009) Mapping species distributions-spatial inference and prediction. Cambridge University Press, Cambridge

Gallagher RV, Beaumont LJ, Hughes L, Leishman MR (2010) Evidence for climatic niche and biome shifts between native and novel ranges in plant species introduced to Australia. J Ecol 98:790-799

GIEC (2007) Climate change 2007: synthesis report. An assessment of the intergovernmental panel on climate change

Guisan A, Thuiller W (2005) Predicting species distribution: offering more than simple habitat models. Ecol Lett 8:993-1009

Guo QH, Liu Y (2010) ModEco: an integrated software package for ecological niche modeling. Ecography 33:637-642

Guo Q, Kelly M, Graham C (2005) Support vector machines for predicting distribution of sudden oak death in California. Ecol Model 182:75-90

Guyon I, Elisseeff A (2003) An introduction to variable and feature selection. J Mach Learn Res 3:1157-1182

Harris RJ, Rees J (2004) Ant distribution database. www. landcareresearch.co.nz/research/biocons/invertebrates/ants/ distribution. Accessed on 01 April 2011

Heller NE, Gordon DM (2006) Seasonal spatial dynamics and causes of nest movement in colonies of the invasive Argentine ant (Linepithema humile). Ecol Entomol 31:499-510

Hellmann JJ, Byers JE, Bierwagen BG, Dukes JS (2008) Five potential consequences of climate change for invasive species. Conserv Biol 22:534-543

Hijmans RJ, Cruz M, Rojas E (2001) Computer tools for spatial analysis of plant genetic resources data: 1. DIVA-GIS. Genet Resour Newsl 127:15-19

Hijmans RJ, Cameron SE, Parra JL, Jones PG, Jarvis A (2005) Very high resolution interpolated climate surfaces for global land areas. Int J Climatol 25:1965-1978

Hoffmann BD (2010) Ecological restoration following the local eradication of an invasive ant in northern Australia. Biol Invasions 12:959-969

Hoffmann BD, Parr CL (2008) An invasion revisited: the African big-headed ant (Pheidole megacephala) in northern Australia. Biol Invasions 10:1171-1181

Hoffmann BD, Andersen AN, Hill GJE (1999) Impact of an introduced ant on native rain forest invertebrates: pheidole megacephala in monsoonal Australia. Oecologia 120:595604

Holway D, Lach L, Suarez AV, Tsutsui ND, Case TJ (2002) The causes and consequences of ant invasions. Annu Rev Ecol Syst 33:181-233

IUCN SSC Invasive Species Specialist Group (2012) Global invasive species database. Pheidole megacephala. http:// www.issg.org/database. Reviewed by Hoffmann B. Accessed 24 January 2012

Jarnevich CS, Reynolds LV (2011) Challenges of predicting the potential distribution of a slow-spreading invader: a habitat 
suitability map for an invasive riparian tree. Biol Invasions 13:153-163

Jenkins CNC et al (2011) Global diversity in light of climate change: the case of ants. Divers Distrib 1-11. doi: 10.1111/j.1472-4642.2011.00770.x

Jimenez-Valverde A, Peterson AT, Soberon J, Overton JM, Aragon P, Lobo JM (2011) Use of niche models in invasive species risk assessments. Biol Invasions 13:2785-2797

Klamt M, Thompson R, Davis J (2011) Early response of the platypus to climate warming. Glob Change Biol 17: 3011-3018

Lach L, Hooper-Bui LM (2010) Consequences of ant invasions. In: Lach L, Parr CL, Abbott KL (eds) Ant ecology. Oxford University Press, New York, pp 261-286

Liu XA, Guo ZW, Ke ZW, Wang SP, Li YM (2011) Increasing potential risk of a global aquatic invader in Europe in contrast to other continents under future climate change. PLoS One 6:e18429

Lorena AC, Jacintho LFO, Siqueira MF, Giovanni RD, Lohmann LG, de Carvalho ACPLF, Yamamoto M (2011) Comparing machine learning classifiers in potential distribution modelling. Expert Syst Appl 38:5268-5275

Lowe S, Browne M, Boudjelas S, De Poorter M (2000) 100 of the World's Worst Invasive Alien Species-a selection from the Global Invasive Species Database

Manel S, Dias J, Ormerod S (1999) Comparing discriminant analysis, neural networks and logistic regression for predicting species distributions: a case study with a Himalayan river bird. Ecol Model 120:337-347

Maravelias C, Haralabous J, Papaconstantinou C (2003) Predicting demersal fish species distributions in the Mediterranean Sea using artificial neural networks. Mar Ecol Prog Ser 255:240-258

Menke SB, Holway DA (2006) Abiotic factors control invasion by Argentine ants at the community scale. J Anim Ecol 75(2):368-376

Murray KA, Retallick RWR, Puschendorf R, Skerratt LF, Rosauer D, McCallum HI, Berger L, Speare R, VanDerWal J (2011) Issues with modelling the current and future distribution of invasive pathogens. J Appl Ecol 48:177-180

Pearce J, Ferrier S (2000) Evaluating the predictive performance of habitat models developed using logistic regression. Ecol Model 133:225-245

Pearman PB, Guisan A, Broennimann O, Randin CF (2008) Niche dynamics in space and time. Trends Ecol Evol 23:149-158

Petitpierre B, Kueffer C, Broennimann O, Randin C, Daehler C, Guisan A (2012) Climatic niche shifts are rare among terrestrial plant invaders. Science 335:1344-1348

Phillips SJ, Anderson RP, Schapire RE (2006) Maximum entropy modeling of species geographic distributions. Ecol Model 190:231-259

Rabitsch W(2011) The hitchhiker's guide to alien ant invasions. BioControl 56:551-572

Rödder D, Lötters S (2009) Niche shift versus niche conservatism? Climatic characteristics of the native and invasive ranges of the Mediterranean house gecko (Hemidactylus turcicus). Glob Ecol Biogeogr 18:674-687
Roura-Pascual N, Suarez AV, Gomez C, Pons P, Touyama Y, Wild AL, Peterson AT, Gómez C (2004) Geographical potential of Argentine ants (Linepithema humile Mayr) in the face of global climate change. Proc R Soc Lond Ser B Biol Sci 271:2527-2534

Roura-Pascual N, Brotons L, Peterson AT, Thuiller W (2009) Consensual predictions of potential distributional areas for invasive species: a case study of Argentine ants in the Iberian Peninsula. Biol Invasions 11:1017-1031

Roura-Pascual N et al (2011) Relative roles of climatic suitability and anthropogenic influence in determining the pattern of spread in a global invader. Proc Natl Acad Sci USA 108:220-225

Sala OE et al (2000) Global biodiversity scenarios for the year 2100. Science 287:1770-1774

Sanders NJ, Lessard JP, Fitzpatrick MC, Dunn RR (2007) Temperature, but not productivity or geometry, predicts elevational diversity gradients in ants across spatial grains. Glob Ecol Biogeogr 16:640-649

Stiels D, Schidelko K, Engler JO, van den Elzen R, Rodder D (2011) Predicting the potential distribution of the invasive Common Waxbill Estrilda astrild (Passeriformes: Estrildidae). J Ornithol 152:769-780

Sutherst RW, Bourne AW (2009) Modelling non-equilibrium distributions of invasive species: a tale of two modelling paradigms. Biol Invasions 11:1231-1237

Suwabe M, Ohnishi H, Kikuchi T, Kawara K, Tsuji K (2009) Difference in seasonal activity pattern between non-native and native ants in subtropical forest of Okinawa Island, Japan. Ecol Res 24:637-643

Vanderwoude C, de Bruyn LAL, House APN (2000) Response of an open-forest ant community to invasion by the introduced ant, Pheidole megacephala. Austral Ecol 25:253259

Vitousek PM, Dantonio CM, Loope LL, Rejmanek M, Westbrooks R (1997) Introduced species: a significant component of human-caused global change. N Z J Ecol 21:1-16

Walters AC, Mackay DA (2004) Comparisons of upper thermal tolerances between the invasive argentine ant (Hymenoptera: Formicidae) and two native Australian ant species. Ann Entomol Soc Am 97:971-975

Walther $\mathrm{G}$ et al (2009) Alien species in a warmer world: risks and opportunities. Trends Ecol Evol 24:686-693

Ward DF (2007) Modelling the potential geographic distribution of invasive ant species in New Zealand. Biol Invasions 9:723-735

Webber BL, Le Maître DC, Kriticos DJ (2012) Comment on "Climatic niche shifts are rare among terrestrial plant invaders". Science 338:193

Wetterer JK (2007) Biology and impacts of Pacific Island invasive species. 3. The African big-headed ant, Pheidole megacephala (Hymenoptera : Formicidae). Pac Sci 61: 437-456

Wolmarans R, Robertson MP, van Rensburg BJ (2010) Predicting invasive alien plant distributions: how geographical bias in occurrence records influences model performance. J Biogeogr 37:1797-1810 